\title{
Advanced System for the Safety of Vehicles
}

\author{
Priya Bhagwan Munde ${ }^{1}$, Prof. Dr. Achala Deshmukh ${ }^{2}$ \\ Electronics and Telecommunication, Sinhgad College of Engineering, Vadgaon, Pune, India ${ }^{1,2}$
}

\begin{abstract}
The idea to save the life of vehicle as well as life of Driver is proposed in this paper. This safety system monitors major accident causing parameters of vehicles: seatbelt, high speed, alcohol consumption, accident location etc. Proposed system will monitor all these parameters with the help of sensors and send the data on Android application which is installed in mobile of one of the family members of Driver where someone can check the status as well as track the location of vehicle. If some mishap occurred or if driver found with no seat belt, drunk, or driving vehicle with high velocity then Driver's current status will be sent by text message. If Driver found drunk then the ignition system won't work to avoid any fatal cases.
\end{abstract}

Keywords: Raspberry-Pi, Vibration Sensor, IR Sensor, MQ3 sensor, Hall-Effect sensor

\section{INTRODUCTION}

It Accidents are unplanned, unintentional act that can lead to death or damage of human life. We all know recently count of vehicles have been increased so as rate of accidents too, causing deaths and damages of human life and vehicle properties. Accidents are unplanned no one can predefine the cause and occurrence but at least one can surely avoid the risk of severe damage. There are different kind of accidents but Specially accidents by vehicles involve aviation, traffic collision, train wrecks, sailing ships, bicycles, motor vehicles wreck and etc. Falls and vehicle collisions are most common causes of accidents, according to National centre of health statistics following are accident rate per year per 1000 people.

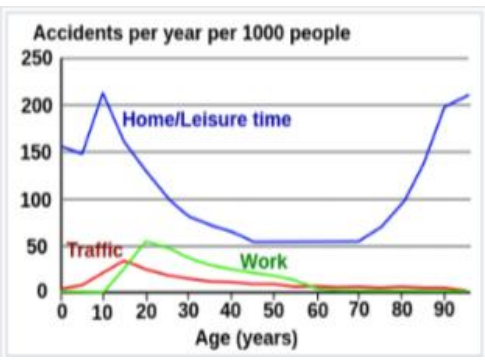

Fig-1: Accident Rate per year per thousand people

According to road statistics of India, one person die every four minutes just because of road accidents, Government has done so many things to prevent the accidents like posting slogans besides the road to make people aware of the severity of accidents, roads have been marked with read caution signs, vehicles are coming up with seat belt, antiskid break system, reflectors, air bag facilities etc. Seat belts are important feature for safety of vehicles. NHTSA statistic has declared that $63 \%$ of people who died in fatal cases did not worn their seat belts. Having seatbelt systems minimize the risk of serious damage and fatality. Seatbelts provides protection to the internal organs in an accident as it holds back the forward movement of the body to a great extent. seatbelts protect against neck and head injuries by lowering head contacts and keeps the passenger in place. The best thing one can do to avoid accident is to have better control of vehicles. Everyone should realize that their life is too important than any other thing. If the speeding or rush is taking you towards death then how one can take risk of driving vehicle with high speed. Find out reasons that force you to increase the speed? Is there that need to speed your vehicle when there is another driver nearby? Or, is this something you do to manage with the traffic? Or, do you just enjoy racing or over-taking? It is really important to lower the speed while on narrow roads, nearing schools, rural areas, hilly areas, low visibility, Wet roads and speed are a perfect combination for accident. Road safety is also important effort of the government and people. The Government administration must care about the conventional condition of the roads and should enforce strict bonding with traffic rules, but careful driving and the right perception of people will be the key to have accident free driving. There are so many lifesaving technics but still we do lack in saving the life of people by greater extent, because in India people won't follow the rules until someone won't be there to make them follow the rules. That's why we have proposed one system in which if some rules has been broke by any Driver, his or her family member will be notified about the action done by the Driver so as someone can watch driver and make sure that driver will not do something that will cause him to have severe injury. 


\section{EXISTING SYSTEM}

Safety System for vehicle is the study and practice plot, construction and regulation to minimize the occurrence and impact of the traffic collisions.

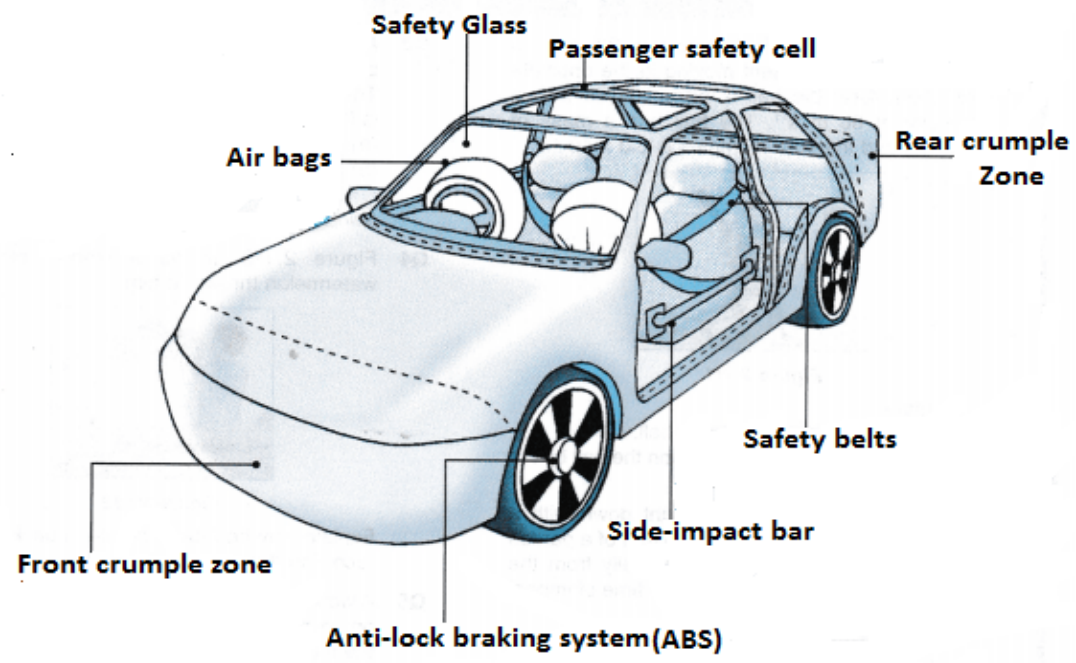

Fig-2: Safety Systems in vehicle

Airbag: Airbags are safety device implemented in many vehicles. When a car collides with something, it loses its speed rapidly. An accelerometer in car detects the change of speed, if this change is great enough, then the accelerometer makes the airbags on. Normal Collision does not create force to do complete the task. An airbag circuit send the current through a heating element . The heating element instigate a chemical explosive. In older airbags sodium a zide were used as their explosive; newer use different chemicals. As the explosive burns, it produces a large amount of harmless gas that floods into a nylon bag packed behind the steering wheel, which causes less harm to the driver and passengers.

Anti-Lock braking System: Antilock braking is a safety system which prevents wheels to completely locking out. ABS prevent Locking of wheels, avoiding uncontrollable skidding of vehicles and lowers the distance travelled without skidding. ABS improve vehicle control and decrease the Severity of skidding of vehicles. ABS includes a central Electronic Control Unit (ECU), four wheel speed sensors, and two hydraulic valves within the brake hydraulics. ABS system has four speed sensors attached to wheels, these sensors will sense when the wheels are going to lock up, modulating unit release the brake pad on that wheel this way the wheels will be allowed to spin during braking.

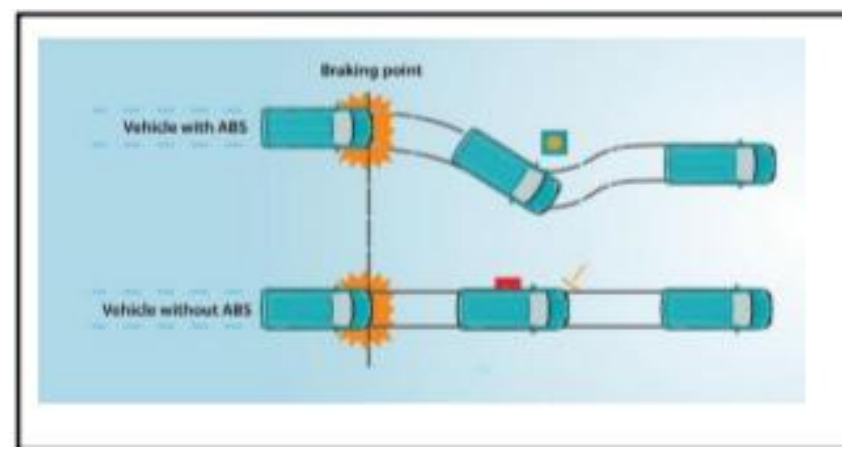

Fig-3: ABS System working

This will allow the steering to function after sudden brake too, which cause no skidding of vehicles. Sensors connected in vehicles will sense the speed of wheels, and if the speed of vehicle is deacce legating at high rate then it takes controls and applies brake in pulse form. The ECU constantly check the rotational speed of each wheel, if it detects the wheel moving significantly different than the maintained speed of the vehicle, it decides whether to lock wheels or not, ABS system prevent complete locking the wheels and so as to skidding of vehicle. OCS [Occupant Classification System]: Occupant classification System is important safety system that is developed to detect presence of child or adult in front passenger seat and for their safety prevent air bag deployments. OCS identifies Occupant below the system weight designation, in front passenger seat cushion or who is seated improperly, the system will automatically 
Vol. 8, Issue 6, June 2019

turn off the passenger airbag. The OCS system works very easily, when ignition system turns on, the OCS system will detect whether anyone seated in front passenger seat or not, and accordingly turn the Airbag system on or off. Proposed Safety System: Methodology behind the project is to interface all sensors to Raspberry-Pi, Sensors will send the captured data to Raspberry-Pi which is wirelessly connected to Android Application, will decide what to transmit according to input.

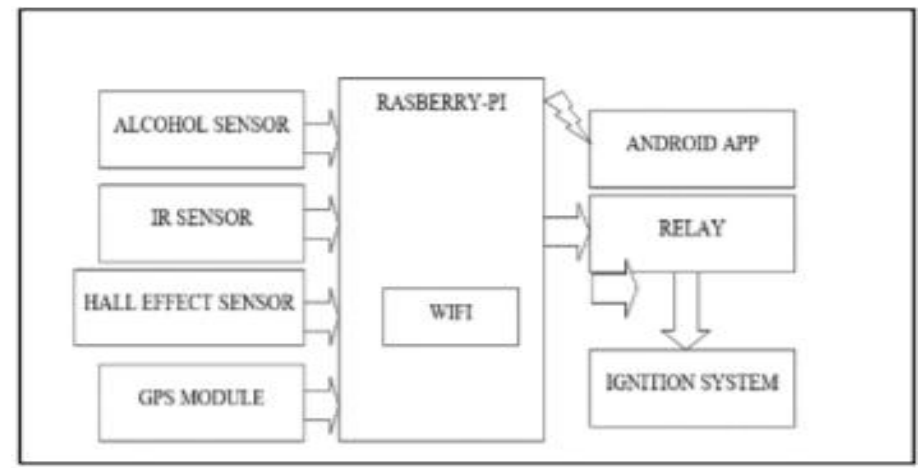

Fig- 4: Block Diagram of Proposed System

Here we propose a framework where the individual is identified for liquor level speed of vehicle, seat belt is wearing or not to stay away from accidents. Drivers will be detected for alcohol consumption by his breath before they begin their vehicle. Let's consider alcohol sensor as the example Alcohol sensor is connected to input of raspberry-pi that detect whether driver is drunk or not.

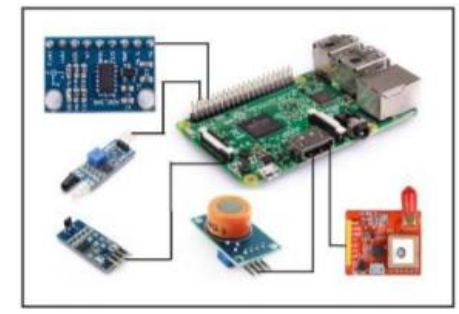

Fig-5: Hardware Interfacing

If driver is drunk than ignition system connected output pin of Raspberry Pi will get locked, at the same time registered mobile number will be notified about the status and location of driver. IR sensor is also connected to input to identify driver is wearing seat belt or not and also when car motor starts hall-effect sensor is connected to Raspberry-Pi detect the speed of the vehicle. In another framework, the individual is identified for wearing seat belt in his body to stay away from accidents. It detected before they begin their vehicle. Driver will be detected by a sensor once he seated on the driver seat by IR Sensor. In this system we are continuously monitoring the speed of vehicle and vibration sensor to avoid accident.

\section{RESULT}

\begin{tabular}{|c|c|c|c|c|c|c|c|}
\hline \multirow[b]{3}{*}{$\begin{array}{c}\text { No.of } \\
\text { Samples }\end{array}$} & \multirow{3}{*}{$\begin{array}{c}\text { Operting } \\
\text { Voltage of } \\
\text { MQ-3 } \\
\text { Sensor }\end{array}$} & \multicolumn{6}{|c|}{ ALCOHOL. SENSOR MO-3 OUTPUT SAMPLES IN PPM } \\
\hline & & $\begin{array}{l}0 \% \\
10 \%\end{array}$ & $\begin{array}{l}11 \% \\
20 \% 6\end{array}$ & $\begin{array}{l}21 \% \\
30 \%\end{array}$ & $\begin{array}{l}31 \% \\
40 \%\end{array}$ & $\begin{array}{l}56 \% \\
60 \%\end{array}$ & $\begin{array}{l}\text { Above } \\
60 \%\end{array}$ \\
\hline & & $\begin{array}{l}\text { Red } \\
\text { Line }\end{array}$ & $\begin{array}{l}\text { Sky } \\
\text { Blue }\end{array}$ & Green & Yellow & Blue & Black \\
\hline 1 & $0 \mathrm{v}$ & 0 & 0 & 0 & 0 & 0 & 0 \\
\hline 2 & $0.5 \mathrm{v}$ & 0 & 22 & 82 & 76 & 163 & 213 \\
\hline 3 & Iv & 30 & 30 & 98 & 102 & 332 & 312 \\
\hline 4 & $15 \mathrm{v}$ & 35 & 98 & 193 & 196 & 556 & 619 \\
\hline 5 & $2 v$ & 52 & 115 & 223 & 234 & 623 & 782 \\
\hline 6 & $25 \mathrm{v}$ & 66 & 135 & 283 & 294 & 762 & 886 \\
\hline 7 & $3 v$ & 79 & 142 & 297 & 315 & 782 & 889 \\
\hline 8 & $3.5 \mathrm{v}$ & 91 & 147 & 297 & 317 & 784 & 889 \\
\hline 9 & $4 v$ & 93 & 148 & 297 & 317 & 785 & 889 \\
\hline 10 & $45 \mathrm{v}$ & 98 & 150 & 297 & 319 & 790 & 893 \\
\hline 11 & $5 v$ & 98 & 155 & 299 & 319 & 792 & 894 \\
\hline
\end{tabular}

Table 2: Output of Mq3 Within Operating Range 
Vol. 8, Issue 6, June 2019

The Alcohol Sensor that is MQ3 is a sensor which detect alcohol consumption, and here is the theoratical output with Graph that shows how the particular sensor works within its operating volatge. Limit has been set by developer to establish the proper structure. If the alcohol intake goes high than the $60 \%$ of the reference limit then the ignition system will get locked, and driver wont able to drive the vehicle.

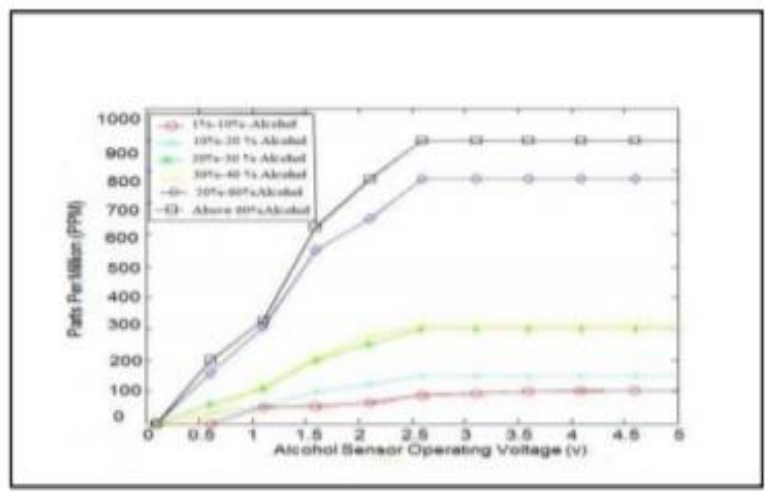

Fig-6: Graph Plot- Ppm Vs Mq3 Output Voltage

If Vehicle met with accident, then vibration sensor will sens the vibration of accident, and will send the message to one of the family member and send location of driver. As per the hardware as shown above, if vibration is given a jerk it will indicate the vibration is detected as below. If rather than using digital sensor if we use analog sensor, the output will be more appropriate and precise.

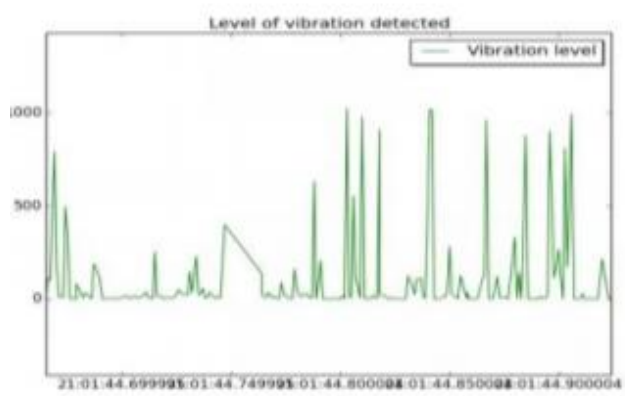

Fig-7: Level of Vibration

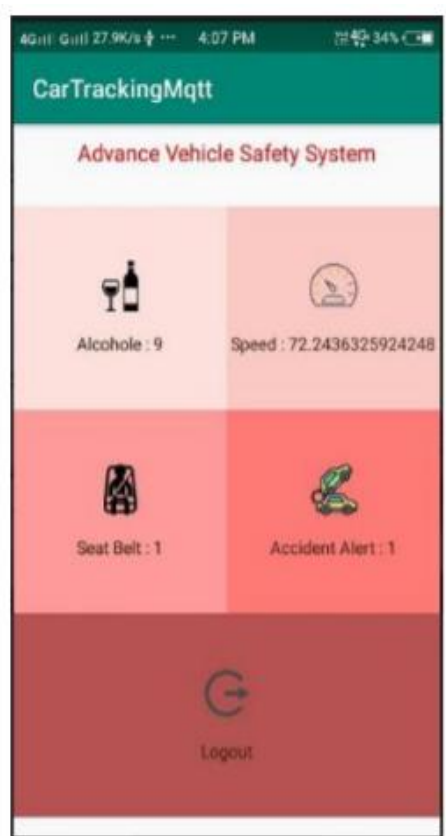

Fig-8: Outut of Android App 
Vol. 8, Issue 6, June 2019

Following results gives working direction of proposed model. During normal operation, when the authorized person open door of the vehicle and sits at the front sit of the car, then he will be monitored, and checked whether he is drunk or not, if he founds drunk then the ignition system will not work, the particular limit of alcohol has been set, Person or driver will be monitored for the alcohol consumption, if his consumption exceeds than the level that has been set then message will be sent to one of his family member expressing the condition of driver i.e. Drunk and location of vehicle is also sent by using GPS model. In same manner the Speed, Seat belt and vibration is monitored. Output of all the parameters will be sent on Android Application which is in the mobile of family member.

\section{CONCLUSION}

Here we have implemented a system for vehicle safety using raspberry-pi and some sensors to secure vehicle and driver of the vehicle. It may decrease the accidents and fatal cases. Actual implementation of this system will establish a beneficial result. For future enhancement, we may add this system to every vehicle running on road to avoid damage of vehicle as well as life. Develop safety system using combination of RFID system, GPS with high speed processor. The system can have latest technology and optimized algorithmic program with moderate value. The system might target correct point prediction and period position of car. The system will be put in payload, trucks, buses, cars and boats.

\section{REFERENCES}

[1]. Benjamin Coifman, David Beymer, Philip McLauchlan, Jitendra Malik, "A real-time computer vision system for vehicle tracking and traffic surveillance," Transportation research part C6, 1998.

[2]. Akande Noah Oluwatobi, "A GPS based automatic vehicle location system for bus transit," 1999.

[3]. Ankit Kesharwani, Vaishali Sadaphal, Maitreya Natu, "Empowering bus transportation system using wireless sensor networks," 2000.

[4]. Kunal Maurya, Mandeep Singh, Neelu Jain, "Real time tracking system using GSM and GPS technology - an anti theft tacking system," International Journal of Electronics and Computer Science Engineering, volume 1, number 3, 2006.

[5]. M.S. Joshi, Deepali V. Mahajan, "Arm 7 Based Theft Control Accident Detection and Vehicle Positioning System", International Journal of Innovative Technology and Exploring Engineering, vol. 4, no. 2, July 2014.

[6]. S.S. Pethakar, N. Srivastava, S.d. Suryawanshi, "RFID GPS and GSM Based Vehicle Tracing and Employee Security System", International Journal of Advanced Research in Computer Science and Electronics Engineering, vol. 1, no. 10, Dec 2012.

[7]. Pravada P. Wankhade, S.O. Dahad, "Real Time Vehicle Locking and Tracking System using GSM and GPS Technology-An Anti-theft System", International Journal of Technology And Engineering System, vol. 2, no. 3, Jan-March 2011 